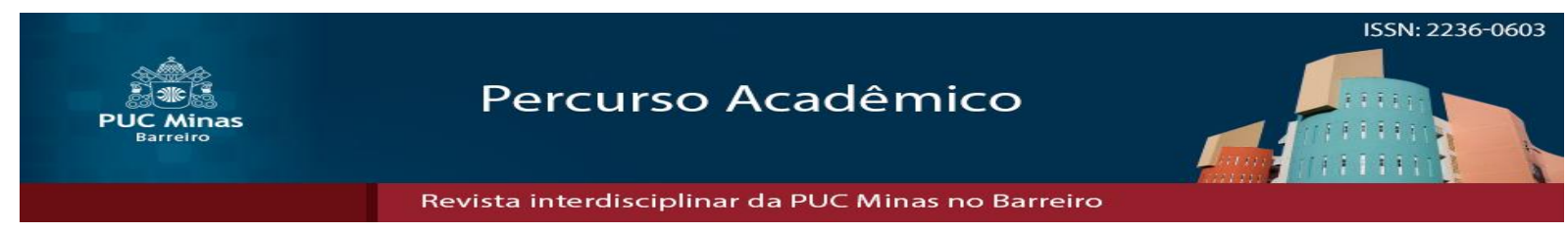

\title{
Avaliação da implantação de um ERP em uma empresa pública: estudo de caso na EPAMIG
}

\section{Evaluation of the implementation of an ERP in a public company: a case study at EPAMIG}

\author{
Mateus Henrique de Aguiar Diniz ${ }^{1}$ \\ Adriane Maria Arantes de Carvalho ${ }^{2}$
}

\section{Resumo}

Atualmente os sistemas ERP têm fundamental importância na arquitetura de informação da maioria das empresas do setor privado. Os sistemas de gestão integrado podem ser vistos como uma ferramenta que organiza o fluxo de informações entre as diferentes atividades da empresa, facilitando a integração da informação e dos processos. Muitos estudos analisaram o processo de implantação dos sistemas ERP em empresas privadas, entretanto, poucas pesquisas têm-se dedicado à avaliação da implantação de sistemas ERP em empresas públicas. Assim, o principal objetivo deste artigo é avaliar a implantação de um sistema integrado de gestão na Empresa de Pesquisa Agropecuária de Minas Gerais (EPAMIG), destacando os cenários antes e depois da implantação do sistema ERP. Foi realizado um estudo de caso e a coleta de dados utilizou entrevistas e questionários. De acordo com os resultados, evidenciou-se que um sistema ERP trouxe melhorias significativas para o processo de requisição de material, com informações exatas e atualizadas, integração das informações entre os setores e a minimização do retrabalho. No entanto, foi identificada a dificuldade dos usuários em aprender a utilizar o sistema o que aponta para uma eventual falha no treinamento. Sugere-se que a organização estudada reveja a sua política de treinamento e de suporte, com a criação de instrumentos que permitam o registro e a solução dos problemas mais frequentes.

Palavras-chave: Enterprise resource planning (ERP). Processo de Requisição de Material. Gestão pública. Implantação de sistemas.

\begin{abstract}
Currently ERP systems have fundamental importance in the information architecture of most private sector companies. Integrated management systems can be seen as a tool

Artigo recebido em 30 de Abril de 2019 e aprovado em 11 de Julho de 2019

${ }^{1}$ Graduado em Sistemas de Informação pela Pontifícia Universidade Católica de Minas Gerais (PUC Minas).

2 Doutora em Ciência da Informação pela Universidade Federal de Minas Gerais. Professora do Departamento de Administração da Pontifícia Universidade Católica de Minas Gerais (PUC Minas).
\end{abstract}


that organizes the flow of information between the different activities of the company, facilitating the integration of information and processes. Many studies have analyzed the ERP systems implementation process in private companies, however, few studies have been devoted to the evaluation of the ERP systems implementation in public companies. Thus, the main objective of this article is to evaluate the implementation of an integrated management system at the Empresa de Pesquisa Agropecuária de Minas Gerais (EPAMIG), highlighting the scenarios before and after the implementation of the ERP system. A case study was conducted and the data collection used interviews and questionnaires. According to the results, it was evidenced that an ERP system brought significant improvements to the material requisition process, with accurate and updated information, integration of information among sectors and minimization of rework. However, it was identified the difficulty of users in learning to use the system which points to a possible failure in training. It is suggested that the organization could review its training and support policy, with the creation of tools to register the recording and resolution of the most frequent problems.

Key-words: Enterprise Resource Planning (ERP). Material Requisition Process. Public management. Deployment evaluation.

\section{Introdução}

Os sistemas de informação estão cada vez mais presentes nas organizações, tornandose componentes imprescindíveis dos seus processos de negócio. De uma maneira em geral, o uso da tecnologia da informação junto à gestão tem produzido resultados positivos para as organizações, sejam elas privadas ou públicas. Os sistemas integrados de gestão, do inglês Enterprise Resource Planning (ERP), tornaram-se tendência e passaram a ser vistos como uma ferramenta de fundamental importância para proporcionar a agilidade necessária nesse contexto competitivo.

De acordo com Sena e Guarnieri (2015), a administração pública tem enfrentado diversos desafios no aprimoramento da gestão de seus processos, adotando novas práticas e tecnologias, e importando práticas consideradas bem-sucedidas, na iniciativa privada. A utilização de sistemas ERP no setor público ainda é restrita e poucos são os casos disponíveis na literatura. (FERREIRA et al, 2012). Porém o uso do ERP no setor público pode ser de grande importância para as organizações pois, como ressaltam Sena e Guarnieri (2015), a visibilidade interna e externa do fluxo de processos em uma organização pública proporciona o conhecimento exato dos fatos administrativos e de seus motivadores, levando a organização a um elevado nível de transparência e eliminando o retrabalho. No entanto, deve-se tomar muito cuidado ao implantar um ERP, pois a utilização desses sistemas se caracteriza por uma mudança organizacional, não apenas tecnológica. 
Em Minas Gerais, a Empresa de Pesquisa Agropecuária de Minas Gerais (EPAMIG) vem utilizando um sistema ERP desde 2012. Após a implantação do ERP vários usuários vêm encontrando dificuldades em realizar algumas tarefas no sistema. Surgiram algumas indagações: os problemas apareceram porque os usuários tiveram dificuldades na adaptação ao novo processo ou têm resistência ao novo sistema? Ou ainda, por tratar-se de uma empresa pública, os usuários apresentam um comportamento de uso diferente dos observados na literatura para empresas privadas?

Com a finalidade de refletir sobre estas questões, o objetivo geral deste trabalho é analisar o impacto da implantação de um ERP na empresa EPAMIG, especificamente no processo de requisição de material. Para que se possa alcançar esse objetivo, foram estabelecidos os seguintes objetivos específicos: a) comparar o processo de requisição de material antes e depois da implantação do módulo ERP; b) avaliar a utilização do módulo pelos usuários.

A relevância deste trabalho está em apresentar uma análise do impacto de implantação de ERP numa empresa pública. Diante da falta de casos de encontrados na literatura sobre assunto, justifica-se a importância de pesquisas que procurem analisar a implantação de ERP não apenas no âmbito de organização privada, e também de contribuir para o entendimento do impacto percebido pelos usuários em relação a esse tipo de sistema.

\section{Sistemas Integrados de Gestão}

Os sistemas integrados de gestão (ERP), são considerados como uma ferramenta de Tecnologia da Informação (TI) que apoia o gerenciamento de informações. O’Brien e Marakas destacam que "o ERP é a espinha dorsal dos negócios eletrônicos, uma arquitetura de transmissão que liga todas as funções de uma empresa" (O'BRIEN; MARAKAS, 2013, p.269). Levando em consideração a perspectiva dos autores, pode-se dizer que um sistema ERP atua no planejamento de recursos empresariais e possui como principal função a informatização dos processos administrativos, conseguindo integrar os setores da empresa em um só ambiente de trabalho.

Souza e Zwicker (2003) entendem que os sistemas ERP podem ser definidos como sistemas de informação integrados, adquiridos na forma de pacotes comerciais de software de 
grande abrangência funcional. Para os autores, os sistemas ERP são geralmente divididos em módulos, que representam conjuntos de funções que normalmente atendem a um ou mais departamentos da empresa. Em muitas empresas existem sistemas específicos para cada departamento, que atendem às demandas internas dos mesmos, porém com a implantação de um ERP, os sistemas próprios de cada setor deixam de existir dando lugar a um único sistema que armazena, automatiza e gerencia todos os processos da empresa.

Tem-se que um ERP deve fornecer suporte à empresa controlando e integrando todos os seus processos. Neste sentido, Laudon e Laudon (2014) destacam que o ERP possibilita que ocorra um fluxo de informações contínuo único e consistente, de uma forma que atenda a organização como um todo. Assim sendo, Souza e Zwicker (2003) reiteram que um ERP necessita de um banco de dados unificado. Portanto, de uma forma geral, os dados que são utilizados por um módulo são armazenados no banco de dados unificado, para que assim possam ser utilizados por outros módulos caracterizando os ciclos de interações de informação entre os módulos, ou seja, integrando as informações da organização. Essa base de dados permite, então, ter uma melhor visão dos processos de qualquer área ou setor em tempo real e, com isso, o gerente detém informações precisas e oportunas para the apoiar na coordenação diária e na tomada de decisões gerenciais. Para Ptak (2004), um dos principais aspectos do ERP é justamente a sua habilidade em centralizar a informação relevante numa única base de dados.

\subsection{Implantação de sistemas ERP}

De acordo com Souza e Zwicker (2003), a adoção de um sistema ERP pela empresa envolve várias etapas. Estas baseiam-se num modelo de ciclo de vida de sistemas ERP, que envolve: a decisão de adoção do sistema e a escolha do software; sua implantação; sua utilização; e, finalmente, sua manutenção ou aprimoramento.

Decisão e seleção constituem uma mesma etapa do processo de implantação dos sistemas ERP porque a decisão de a empresa adotar ou não esse recurso ocorre concomitantemente com a seleção do fornecedor (SOUZA; ZWICKER, 2003).

A implementação é a segunda etapa do ciclo de vida de sistemas ERP e pode ser definida como o processo pelo qual os módulos do sistema são colocados em funcionamento na organização, o que significa iniciar a utilização do sistema no processamento de transações 
empresariais (SOUZA; ZWICKER, 2003). O processo de implementação é realizado em várias etapas de adaptação, uma para cada módulo ou grupo de módulos. É o momento no qual são realizados os procedimentos de ajuste do pacote ERP, ou seja, são realizadas modificações para que possam ser utilizados sob demanda em determinada empresa (SOUZA; ZWICKER, 2003).

O início da utilização do sistema exige que ele tenha sido adequadamente parametrizado, customizado (se necessário) e que: os funcionários que irão interagir com o sistema estejam devidamente treinados. Além disso as condições para obter suporte e auxílio devem ter sido disponibilizadas de forma adequada (SOUZA; ZWICKER, 2003).

Entre essas etapas, a implantação é, sem dúvida, a mais crítica do processo, uma vez que é a etapa que provoca mudanças na empresa. Além disso, ao considerar a etapa de manutenção como uma etapa de novas, periódicas e contínuas implantações, percebe-se mais uma vez sua importância. De acordo com Ptak (2004), um cuidadoso plano de implantação deve considerar as expectativas e receios dos stakeholders.

\subsubsection{Parâmetros para implantação}

Os projetos de implantação de sistemas empresariais integrados normalmente têm grande impacto sobre a empresa. Além disso, demandam grandes volumes de recursos humanos e financeiros (COLANGELO FILHO, 2001).

Segundo Colangelo Filho (2001), a implantação de um ERP é algo muito complexo, pois envolve muitas atividades e recursos, e sempre causa impacto na cultura da empresa provocando uma série de mudanças: na estrutura gerencial; nos processos de negócio; no modelo de gestão; e principalmente, nas pessoas. Por este motivo, o processo de implantação é estruturado através de um projeto. E como todo projeto, este, deve ser gerenciado de maneira adequada a fim de atingir seus objetivos previamente definidos.

A implantação é decisiva no que diz respeito à garantia do sucesso futuro do ERP. Um sistema implantado incorretamente pode fracassar quanto ao seu propósito inicial. Para Goncalves e Lima (2010) a organização não deve simplesmente achar que a implantação do sistema resolverá todos os seus problemas. Às vezes os problemas encontram-se nos próprios processos de negócio da empresa. 


\subsubsection{Mudança organizacional decorrente da implantação do sistema ERP}

De acordo com Saccol et al (2003), a implantação do ERP três tipos de mudança: mudanças tecnológicas, relacionadas à mudança na tecnologia da informação e na qualidade da informação, nas técnicas e processos de trabalho, na qualificação das pessoas etc; mudanças estruturais, vinculadas a alterações nos mecanismos de coordenação, nas partes básicas das organizações e nos parâmetros de desenho das organizações; e mudanças comportamentais, associadas à mudança cultural, de visão departamental da organização para uma visão baseada em processos, do grau de motivação dos empregados e nas habilidades e capacidades requeridas das pessoas. Catellino et al, citado por Moura et al (2014) também destaca que são necessárias mudanças nos processos organizacionais, culturais e de negociação e enfatiza a importância da consideração de aspectos técnicos e não técnicos ligados ao ERP.

A implantação de um ERP afeta de uma maneira muito radical os processos, e até mesmo a cultura da empresa, portanto, deve-se ter uma atenção para lidar com essa mudança. Assim,

Ter simplesmente os processos-chave de negócios sob o controle de um sistema ERP não é condição sine qua non para a mudança de gestão, no entretanto, os estímulos criados pelo sistema, ainda de acordo com o próprio autor, constituem uma pressão constante sobre a gestão, no sentido de promover a mudança" (MONTEIRO; SORDI, 2006, p.42).

Na perspectiva de Monteiro e Sordi (2006), a adoção de um ERP propicia diversas melhorias, tais como: o controle maior sobre os processos operacionais; redução da burocracia ao nível mínimo; elevação do faturamento; redução do tempo de faturamento; redução do tempo de prestação de serviços de assistência técnica e a racionalização dos custos operacionais de assistência técnica e de vendas. No entanto, fica claro que junto com o sistema surgem algumas dificuldades como, por exemplo: encontrar no mercado profissionais com qualificação para atuar junto ao sistema; complexidade para a gestão integrada dos negócios, sendo necessário um bom índice de aceitação e uso do sistema pelos colaboradores da organização, pois o contrário poderá ocasionar no insucesso do investimento. Por melhor que seja o sistema, o retorno não será possível se os usuários não utilizarem o sistema. Por isso Ptak (2004) destaca que o projeto de implantação deve incluir o treinamento de todos os usuários, assim como deve lidar com possíveis objeções que eles apresentem.

De acordo com Saccol et al (2004), o ERP em si demonstra agregar valor em relação à variável produção (ganhos de produtividade, escala no uso de software etc.). Ele oferece 
também importantes contribuições para a eficácia organizacional e, especialmente, para a eficiência interorganizacional, facilitando a gestão, integração e comunicação entre diferentes unidades organizacionais.

\section{Procedimentos metodológicos}

Inicialmente foi realizado um levantamento bibliográfico e elaborado o referencial teórico sobre sistemas de gestão integrado. Optou-se pela pesquisa descritiva e o estudo de caso para alcançar os objetivos propostos. Para Gil (2012), as pesquisas descritivas têm como objetivo a descrição das características de determinada população, possibilitando o registro e a interpretação dos fatos, proporcionando assim uma nova visão sobre o cenário estudado. De acordo com Yin (2002), o estudo de caso é uma investigação empírica que investiga um fenômeno contemporâneo dentro de seu contexto da vida real, especialmente quando os limites entre o fenômeno e o contexto não estão claramente definidos como é o caso desse trabalho.

A unidade de análise foi a empresa EPAMIG - uma empresa do setor público, com sede situada na cidade de Belo Horizonte e várias unidades (fazendas) por todo o Estado de Minas Gerais. A escolha pela empresa decorre do fato do autor trabalhar na mesma. O sistema ERP implantado na EPAMIG atende a todas as fazendas e cerca de mil usuários, incluindo os funcionários da sede e os demais funcionários do interior.

O estudo de caso foi realizado por meio de observações feitas no próprio ambiente de trabalho, coleta da documentação do projeto ERP, realização de entrevistas e aplicação de questionários estruturados junto aos usuários do módulo de processos de requisição de material.

O roteiro de entrevista semiestruturado foi elaborado para analisar o processo de implantação e entender o cenário da empresa. A entrevista foi dividida em três partes relacionadas ao ciclo de vida do ERP: decisão e seleção; implementação; avaliação e uso do ERP. O roteiro do questionário possui dois blocos de itens. O primeiro bloco consiste em questões referentes ao sistema legado existente na empresa antes da adoção do sistema ERP. No segundo bloco foi adotado o modelo de Carvalho et al. (2008), com o acréscimo das 
perguntas 7 e 17. As perguntas foram agrupadas por assunto para auxiliar a análise dos dados, como pode ser visto no Quadro 1.

\section{Quadro 1 - Categorias analíticas}

\begin{tabular}{|c|c|}
\hline Categorias & Questões \\
\hline Facilidade & $5-10-11-13-14$ \\
\hline Produtividade & $6-21-22$ \\
\hline Utilidade & $7-8-9-15-16-17-19$ \\
\hline Controles internos & $12-18-20$ \\
\hline Satisfação & $23-24$ \\
\hline
\end{tabular}

Fonte: Elaborado pelos autores

A categoria Facilidade refere-se à facilidade de aprender e usar o sistema. Venkatesh et al, citado por Moura et al (2014), destaca que perguntas relacionadas à facilidade percebida pelo usuário dizem respeito a quanto de esforço deverá ser investido para que utilize o sistema. A categoria Utilidade, trata de como as informações do sistema são úteis. A utilidade percebida remete à crença de uma pessoa sobre o grau que a tecnologia melhorará seu desempenho na sua rotina de trabalho (VENKATESH et al, citado por MOURA et al, 2014). A categoria de Controles internos está relacionada com melhoria do controle das informações disponibilizadas. Na categoria Satisfação estão as perguntas sobre necessidades atendidas.

Foi utilizada uma escala Likert para buscar resultados de acordo com o grau de conformidade dos entrevistados. A escala Likert adotada tem 5 pontos onde cada nível recebeu uma pontuação ou peso, da seguinte maneira: Discordo com peso 1; Discordo com peso 2; Indiferente com peso 3; Concordo com peso 4; Concordo totalmente com 5.

A coleta dos dados ocorreu por meio de entrevistas com os três funcionários que ocupam os cargos de Coordenador web (Entrevistado 1), Coordenador de suporte (Entrevistado 2), e Coordenador de redes (Entrevistado 3). Eles atuam na Assessoria de Informática, trabalham na empresa há mais de 20 anos e participaram de todo o processo de informatização da empresa. A escolha dos respondentes da entrevista seguiu o critério de participação ativa em todo o processo de implantação do sistema. Elas ocorreram no segundo semestre de 2016.

No dia 03/05/2017, foi realizada mais uma entrevista com um Analista de sistemas (Entrevistado 4), que participou diretamente da segunda fase de implantação do ERP. Também foram utilizados documentos de todo o processo de implantação, possibilitando descrever o cenário básico da EPAMIG antes da implantação do sistema ERP. 
Foram convidados a participar da pesquisa os funcionários da empresa que utilizam a Requisição de Material do módulo do ERP adquirido. O convite foi feito via e-mail, contando com uma carta de apresentação do estudo. O e-mail foi enviado para os cinquenta usuários ativos do módulo (população), tanto na sede como nas fazendas, e foram obtidas vinte e nove respostas (amostra). A partir do tamanho da população e do tamanho da amostra foi calculado a margem de erro do questionário que é de $11,91 \%$. O questionário foi construído no Google Forms e ficou disponibilizado entre os dias 12/05/2017 até 26/05/2017.

Desta maneira, a pesquisa de campo utilizou quatro fontes de evidências: a observação, a documentação do processo de implantação, a entrevista e os questionários, gerando análises de natureza quantitativa e qualitativa. Após a coleta dos dados eles foram tabulados utilizando uma planilha do Excel.

Com a definição dos pesos de cada item, foi calculada a média ponderada das respostas em cada questão utilizando o peso para a ponderação, assim como em Carvalho et al. (2008). Valores da média ponderada menores que 3 foram considerados como discordantes e, maiores que 3 , como concordantes, considerando a escala de 5 pontos. 0 valor exatamente 3 foi considerado indiferente. A seguir serão apresentados os resultados obtidos.

\section{Apresentação e análise dos dados}

A Empresa de Pesquisa Agropecuária de Minas Gerais (EPAMIG) é um órgão vinculado à Secretaria de Estado da Agricultura, Pecuária e Abastecimento do Estado de Minas Gerais. Seu propósito principal destina-se ao desenvolvimento a aplicação de pesquisa na área agrícola (tanto de culturas anuais como perenes e pecuárias).

A missão da empresa é pesquisar, capacitar e apresentar soluções e inovações tecnológicas para o desenvolvimento sustentável da agropecuária e da agroindústria, em benefício da sociedade. (EPAMIG, 2016). Alguns programas de pesquisa realizados pela empresa são nas áreas de: Agroenergia, Aquicultura, Cafeicultura, Floricultura, Fruticultura, Olericultura, Pesquisa em Bovinos, Processamento Agroindustrial, Silvicultura e Meio Ambiente.

Com o intuito de contribuir e aperfeiçoar vocações locais e regionais, todos estes programas envolvem a existência de Fazendas Experimentais, as quais encontram-se espalhadas por várias regiões do Estado. 


\subsection{Cenário do Processo de Requisição de Material anterior à implantação do ERP}

O processo anterior de requisição de material partia da necessidade de repor algum material em qualquer setor da empresa. Então era aberta uma solicitação de material para o setor de almoxarifado, por meio de um formulário. O funcionário do setor preenchia o formulário de papel inserindo o código do material, nome e a quantidade desejada. Após isso o chefe do setor o assinava e o formulário era encaminhado, na maioria das vezes por um office boy, ao setor de almoxarifado. Assim que a solicitação chegava ao setor de destino, o funcionário consultava no estoque se existia o material, utilizando uma planilha. Caso o almoxarifado tivesse o material, ele o enviava ao solicitante. Caso não existisse esse material no estoque era feita uma ordem de compra (formulário a ser preenchido). Então era realizado o processo de compra e, com a chegada do material na empresa, ele era entregue ao setor solicitante.

As respostas relativas à situação antes da implantação do sistema ERP na EPAMIG, permitiram esboçar um panorama da situação, como pode ser visto na Tabela 1. Do total de vinte e nove respondentes, vinte e dois conheciam o processo anterior. Esta identificação foi possível pois a pergunta inicial do questionário era: "Você utilizou o antigo sistema de requisição de material?".

Observa-se que as questões 1 e 3 obtiveram médias menores que 3 e baixa taxa de dispersão, demonstrando que os usuários, no geral, não concordam que o sistema anterior facilitava o seu trabalho diário e que o fluxo de informações entre os setores era suficiente. Para eles muita informação ficava perdida ao longo do processo gerando atraso e retrabalho.

\section{Tabela 1 - Situação antes da implantação do ERP}




\begin{tabular}{|c|c|c|c|}
\hline \multirow{2}{*}{\multicolumn{2}{|c|}{ Questões }} & \multicolumn{2}{|c|}{ Parâmetros } \\
\hline & & $\begin{array}{c}\text { Média } \\
\text { ponderada }\end{array}$ & $\begin{array}{l}\text { Desvio } \\
\text { padrão }\end{array}$ \\
\hline 1 & $\begin{array}{l}\text { A forma de realizar uma requisição de material no sistema } \\
\text { anterior facilitava meu trabalho }\end{array}$ & 2,91 & 3,78 \\
\hline 2 & $\begin{array}{l}\text { Era fácil ou óbvio localizar as informações no sistema } \\
\text { anterior. }\end{array}$ & 4,73 & 6,99 \\
\hline 3 & $\begin{array}{l}\text { O fluxo de informações entre os setores era suficiente } \\
\text { para mantê-los alinhados. }\end{array}$ & 2,90 & 3,78 \\
\hline 4 & Estava satisfeito com o sistema anterior. & 3,45 & 3,29 \\
\hline
\end{tabular}

Fonte: dados da pesquisa

A pergunta 2 é a que mais chama atenção, pois uma parcela de usuários conseguia localizar as informações do sistema com facilidade, porém o alto grau de dispersão $(6,99)$, indica que esta facilidade para localizar as informações existia somente para alguns, ou seja, enquanto muitos usuários (dezesseis) conseguiam manusear as informações com extrema facilidade, outros encontravam dificuldades para conseguir acompanhar as informações no sistema.

A questão 4, relativa ao grau de satisfação do usuário com o sistema, obteve média de 3,45 e baixa dispersão, apontando que o sistema anterior era considerado relativamente bom, ou seja, aparentemente atendia as necessidades dos usuários.

\subsection{0 processo de implantação do ERP}

A empresa passou por dois processos distintos: um de implantação inicial do sistema em 2005; e outro para a segunda fase de implantação em 2012. Num primeiro momento a chefia da Assessoria de Informática foi quem decidiu, junto à presidência da empresa, pela implantação do sistema da fornecedora RM Sistemas. Num segundo instante, quando ocorreu a entrada de uma nova chefia da Assessoria de Informática, a empresa passou pela segunda fase de implantação com o objetivo de implantar o sistema ERP de maneira completa. 


\subsubsection{A decisão e escolha do ERP e a implantação inicial}

Antes da implantação do ERP a Assessoria de Informática desenvolvia vários tipos de soluções específicas para cada processo, variando de planilhas até pequenos sistemas. Porém estes sistemas não tinham integração entre si, ou seja, eram sistemas específicos e independentes.

De acordo com o Entrevistado 4, os gestores reclamavam da dificuldade de acesso à informação, bem como da demora em adquiri-las. O principal motivo da escolha do ERP foi a intenção de integrar suas áreas (estoque, compras, patrimônio, financeiro, contábil, fiscal e folha de pagamento), de ter um melhor controle das unidades descentralizadas/filiais e, consequentemente, de gerenciar melhor a empresa. Na época foi solicitado um orçamento a três empresas fornecedoras desse tipo de sistema.

Em meados 2005, após a etapa de seleção, os gestores fecharam contrato com a RM Sistemas. A implantação inicial deu-se em no fim de 2005. Ela apresentou alguns problemas, tais como: falta de documentação de processos internos; pausas no projeto a cada troca de chefias; resistência de funcionários quanto a essa nova tecnologia; falta de comprometimento dealguns setores; e um aumento no prazo decorrente da compra da empresa fornecedora por outra, que acarretou um atraso de cerca de dois anos de duração. Os diversos problemas enfrentados ocasionaram um atraso no cronograma e, consequentemente, um aumento no valor do projeto. Foram implantados somente dois módulos de maneira completa: RM Folha (Módulo referente à Folha de Pagamentos) e RM Liber (Módulo referente à Gestão Fiscal). Os demais módulos ficaram sem conclusão.

De acordo com os Entrevistados 1, 2 e 3, a falta de comprometimento e resistência à tecnologia de alguns funcionários, somados à falta de documentação de processos, comprometeu a fase de levantamento de requisitos. Por esse motivo vários processos não foram incluídos no sistema. Alguns dos processos incluídos, como por exemplo, o processo de requisição de material foram inseridos de maneira incompleta nosistema.

\subsubsection{A segunda fase de implantação do ERP}

Em 2012, com a entrada de uma nova chefia da Assessoria de Informática, a empresa passou pela segunda fase de implantação. Conforme o Entrevistado 4, o seu objetivo principal 
era: obter a melhoria na execução dos processos; e correção daqueles que não se encontravam no sistema, realizando a devida integração entre as áreas. A decisão foi continuar com o ERP já implantado e reestruturá-lo de forma a integrar seus módulos. Então ocorreu a implantação completa do sistema ERP.

A segunda fase de implantação teve início no primeiro semestre de 2012 e durou 1 ano e 7 meses, tendo entrado em operação em 01 de janeiro de 2014. Os módulos foram implantados separadamente, sob demanda, das áreas afins. A própria empresa fornecedora disponibilizou seus analistas/consultores que apoiaram a empresa durante a implantação.

Segundo o Entrevistado 4, o principal desafio foi fazer com que os usuários se envolvessem com a implantação, de modo a alinhar as informações necessárias para a estruturação dos processos e executar as tarefas do projeto. Ainda de acordo com o entrevistado, o impacto maior ocorreu nos setores de Compras, Estoque e Almoxarifado, responsáveis pela entrada de mercadoria/serviços da empresa. Isso ocorreu porque os processos tinham sido inseridos no sistema anterior de maneira incompleta, gerando assim maior dificuldade para os usuários, já que a partir da implantação completa do módulo, ele passou a ser integrado aos demais módulos do sistema.

Nesta fase, a equipe da fornecedora do sistema e a Assessoria de Informática da EPAMIG criaram um cronograma seguindo a metodologia de implantação da própria fornecedora do sistema. Dessa forma, foram levantados e documentados, novamente, todos os processos existentes na empresa. Os procedimentos de levantamento de processos foram realizados por meio de entrevistas com os funcionários de cadaárea.

Segundo os entrevistados, mais uma vez a resistência dos funcionários a fornecer informações para o projeto da segunda fase de implantação foi um dos pontos mais difíceis. Apesar das dificuldades os processos foram totalmente revitalizados, incluindo o processo de requisição de material que, dessa vez, havia sido parametrizado no sistema.

Quanto ao treinamento de usuários, o entrevistado, explicou que o treinamento ocorreu apenas com os usuários-chave e estes repassaram o conhecimento para seus colegas de trabalho. No entanto, no caso de algum usuário sentir a necessidade de algum treinamento, ele pode requisitá-lo junto ao departamento de Recursos Humanos.

\subsubsection{O uso do sistema}


Após a segunda fase de implantação do sistema ERP, o processo de requisição de material passou a acontecer da seguinte forma: quando surge a necessidade de algum material, dentro de qualquer setor da empresa, é aberta uma solicitação de material através do sistema. O funcionário realiza login no sistema e seleciona o material desejado. De maneira automática é realizada a abertura de um workflow. O sistema aguarda aprovação da chefia do setor para prosseguir para próxima etapa. Assim que a chefia aprova a movimentação, a solicitação é exibida para o setor de almoxarifado. A equipe do setor de destino recebe o workflow, que fará de maneira automática a verificação da existência do material no estoque e, caso exista o material em estoque, o funcionário do setor deve aprovar a solicitação, fazendo o recebimento desse movimento para o processo de Baixa de Estoque/Entrega de Material, no qual o workflow é encerrado e o material entregue. Caso o material não conste no estoque, o responsável pelo Almoxarifado encerrará o workflow e em seguida receberá a requisição para o processo de solicitação de compras. Será realizado todo o processo de compra do material e após chegada do material, ele é entregue para o setor solicitante, sendo encerrado o workflow.

De acordo com todos os entrevistados, é possível identificar alguns benefícios após a segunda fase de implantação do sistema ERP, como por exemplo: evita o retrabalho; minimiza o risco de erro; torna a informação disponível no sistema; permite maior controle dos gastos e receitas. No entanto, eles destacam que para melhorar o gerenciamento da empresa deve haver

o empenho de todos os colaboradores envolvidos no projeto.

Ao serem indagados sobre a situação após a implantação do sistema ERP na EPAMIG, os respondentes permitiram esboçar um panorama da situação, conforme a Tabela 2.

Observa-se que as perguntas relacionadas à facilidade (questões 5, 10, 11, 13 e 14) têm médias superiores a 3, com exceção de duas perguntas específicas (questões 10 e 11) que tratam da facilidade de usar e aprender. A questão 5, obteve média de 3,79 e baixa dispersão, apontando que os usuários notaram uma facilidade maior ao utilizar o sistema ERP no dia a dia, quando se compara com o resultado obtido na questão 1 . As questões 13 e 14, tiveram médias de 3,00 e 3,28 e a taxa de dispersão muito baixa, apontando que eles consideravam mais fácil localizar a informação no sistema anterior, conforme resultado obtido na questão 1.

As perguntas que abordam a facilidade de aprender e utilizar o sistema (questões $10 \mathrm{e}$ 11) apresentaram as menores médias do questionário - 2,03 e 2,31 respectivamente - e baixa taxa de dispersão, demonstrando que os usuários, no geral, não concordam que o sistema ERP 
é fácil de usar ou de aprender como usar. Isso demonstra que o sistema ERP requer treinamento para os funcionários, pois possui uma curva de aprendizadogrande.

Em relação à utilidade que o sistema ERP gerou após sua implantação (questões 7, 8, $9,15,16,17$ e 19), obteve-se média ponderada elevada. Este resultado demonstra que, apesar das dificuldades encontradas durante o processo implantação, os usuários acreditam que o sistema proporciona melhorias para ajudá-lo a desempenhar o seu trabalho, com a consolidação da informação, evitando inconsistências e redundâncias, e principalmente reduzindo a complexidade dos processos. No entanto, vale ressaltar a importância de conhecer o funcionamento do processo de requisição de material, pois a medida que tem-se domínio sobre o funcionamento do processo, mais simples fica o entendimento do mesmo no sistema ERP. Esse resultado é semelhante ao obtido por Ferreira et al (2012) num caso de implantação do ERP numa instituição pública de ensino superior. Os usuários que apresentaram dificuldades em utilizar o ERP, a associaram ao fato da preparação (treinamento) ter sido deficiente.

Tabela 2 - Situação depois da implantação do ERP 


\begin{tabular}{|c|c|c|c|}
\hline \multirow{2}{*}{\multicolumn{2}{|c|}{ Questões }} & \multicolumn{2}{|c|}{ Parâmetros } \\
\hline & & $\begin{array}{c}\text { Média } \\
\text { ponderada }\end{array}$ & $\begin{array}{l}\text { Desvio } \\
\text { padrão }\end{array}$ \\
\hline 5 & O sistema ERP facilita o meu trabalho diário. & 3,79 & 4,76 \\
\hline 6 & $\begin{array}{l}\text { O sistema ERP permite que eu realize tarefas mais } \\
\text { rapidamente, aumentando a minhaprodutividade. }\end{array}$ & 3,83 & 5,26 \\
\hline 7 & $\begin{array}{l}\text { Conheço o funcionamento de todo o processo de } \\
\text { requisição de material no sistema ERP. }\end{array}$ & 4,34 & 6,65 \\
\hline 8 & $\begin{array}{l}\text { O sistema ERP permite que eu melhore a qualidade do } \\
\text { meu trabalho. }\end{array}$ & 4,00 & 5,89 \\
\hline 9 & $\begin{array}{l}\text { Considero o sistema ERP muito útil para minhas } \\
\text { atividades. }\end{array}$ & 4,34 & 7,53 \\
\hline 10 & É fácil e rápido aprender como usar o sistema ERP. & 2,03 & 6,87 \\
\hline 11 & Considero o sistema ERP fácil de usar. & 2,31 & 3,96 \\
\hline 12 & $\begin{array}{l}\text { O sistema ERP possui informações exatas, atualizadas e } \\
\text { em um nível apropriado de detalhamento. }\end{array}$ & 4,45 & 8,11 \\
\hline 13 & É fácil localizar informações no sistema ERP. & 3,00 & 2,39 \\
\hline 14 & $\begin{array}{l}\text { O significado de uma informação disponível no sistema } \\
\text { ERP é fácil de localizar ou então é óbvio. }\end{array}$ & 3,28 & 1,92 \\
\hline 15 & $\begin{array}{l}\text { O sistema ERP permite a comparação e consolidação de } \\
\text { informações, sem gerar inconsistências. }\end{array}$ & 3,83 & 5,22 \\
\hline 16 & $\begin{array}{l}\text { A implantação do ERP gerou impactos positivos nas } \\
\text { rotinas de trabalho da organização. }\end{array}$ & 4,00 & 5,07 \\
\hline 17 & O sistema ERP reduz a complexidade dos processos. & 3,97 & 5,36 \\
\hline 18 & $\begin{array}{l}\text { Houve uma melhoria significativa nos controles internos } \\
\text { da empresa gerada pelo sistema ERP. }\end{array}$ & 3,93 & 4,82 \\
\hline
\end{tabular}




\begin{tabular}{l|c|c}
\hline $19 \begin{array}{l}\text { O sistema ERP permite a integração de todas as } \\
\text { informações das diversas áreas da empresa. }\end{array}$ & 4,21 & 6,38 \\
\hline $20 \begin{array}{l}\text { O fluxo das informações entre os setores está mais } \\
\text { organizado por causado sistema ERP. }\end{array}$ & 4,00 & 5,63 \\
\hline $\begin{array}{l}\text { Com o sistema ERP, foi possível minimizar o retrabalho } \\
\text { e a redundância de informaços. }\end{array}$ & 4,14 & 6,06 \\
\hline $\begin{array}{l}\text { É rápido obter informações, pois o sistema ERP é muito } \\
\text { ágil. }\end{array}$ & 3,93 & 5,54 \\
\hline $\begin{array}{l}\text { O sistema ERP atende plenamente as minhas } \\
\text { necessidades, do meu setor e da empresa. }\end{array}$ & 4,14 & 6,10 \\
\hline $\begin{array}{l}\text { Estou plenamente satisfeito com o sistema ERP im } \\
\text { plantado atualmente na empresa }\end{array}$ & 4,14 & 5,85 \\
\hline
\end{tabular}

\section{Fonte: Dados da pesquisa}

É possível observar que os itens relacionados à controles internos (questões 12, 18 e 20) são os que obtiveram a maior média dos dados. Esses resultados reforçam a ideia que o ERP trouxe benefícios para o dia a dia dos funcionários, principalmente se comparado ao cenário anterior. Na primeira parte do questionário, a pergunta relacionada à melhoria dos controles internos indicou uma média inferior a 3 e com um baixo grau de dispersão, evidenciando o descontentamento dos usuários com relação a desorganização da informação. Por sua vez, após a implantação do ERP, esta média subiu significativamente, deixando claro que agora os usuários possuem um controle maior para gerenciar as informações necessárias e principalmente para manter os setores integrados e bem alinhados. Convém ressaltar a alta taxa de dispersão na pergunta 12 , confirmando que a grande maioria dos funcionários (vinte), acreditam que o sistema ERP possui informações exatas e sempre atualizadas.

Conforme os resultados apresentados os usuários estão satisfeitos com a implantação do sistema ERP. Isso pode ser comprovado através das médias 4,14 e 4,14 respectivamente, para as perguntas relacionadas à satisfação do usuário. Se antes da implantação os usuários estavam conformados com o sistema anterior, após a implantação do sistema, ficou claro que as melhorias trazidas junto ao ERP, deixaram os usuários com um nível de satisfação elevado.

No geral, nota-se que grande parte das médias foram elevadas, demonstrando um grau de concordância dos usuários quantos aos benefícios do ERP para a empresa e vai de encontro 
com as opiniões dos entrevistados que indicaram vários benefícios obtidos com a utilização do sistema ERP.

\section{Considerações finais}

O estudo tinha como objetivo a análise do impacto de implantação de ERP numa empresa pública, a EPAMIG. Foi possível comparar o processo de requisição de material antes e depois da implantação do módulo ERP. Convém ressaltar que não houve nenhum tipo de restrição por parte da empresa para a realização do estudo. A limitação mostrou-se presente somente para a coleta de dados por meio de entrevistas e/ou questionários. Os funcionários muitas das vezes não tinham disponibilidade para responder as questões. No entanto, apesar da margem de erro da pesquisa ser de $11,91 \%$, os dados permitem apontar algumas tendências com relação ao uso do módulo ERP estudado.

Observou-se que, de acordo com as respostas do grupo de questões "Produtividade", o processo de requisição de material ficou mais ágil após a implantação do sistema ERP, beneficiando o trabalho diário dos funcionários e fazendo com que se tenham informações atualizadas e consolidadas. Acrescenta-se ainda que no que se refere a "Controles internos", a implantação do sistema ERP na EPAMIG beneficiou a gestão do processo contribuindo na melhoria da comunicação entre os setores bem como a organização de todas as informações. Nota-se também, que após a implantação do sistema, houve a integração de informações entre diversas áreas. Além disso permitiu a comparação e consolidação de informações, gerando assim ganhos na qualidade do trabalho dos funcionários, conforme as respostas do grupo de "Utilidade".

Pode-se inferir que os usuários tiveram retorno satisfatório sobre a implantação do ERP, já que as questões do grupo "Satisfação" obtiveram grande maioria das respostas como positivas (médias acima de 3). Porém percebe-se que, segundo o grupo de questões "Facilidade", os funcionários tiveram dificuldades em aprender a utilizar o novo sistema o que impacta diretamente em sua utilização diária. Ressalta-se o destaque negativo, indicado pelos usuários, que trata das perguntas 10 e 11 que obtiveram as menores médias e ambas estão relacionadas à facilidade de uso do sistema. Estas perguntas deixam claro que o treinamento passado ao usuário não foi suficiente para o seu entendimento quanto aos processos do sistema ERP. Ressalta-se aqui a importância do treinamento para a consolidação do conhecimento sobre o processo e sobre a utilização do sistema. Para que isso venha a ocorrer 
sugere-se que a organização estudada reveja a sua política de treinamento e de suporte, com a criação de instrumentos que permitam o registro e a solução dos problemas mais frequentes.

Em se tratando de um estudo de caso, as conclusões desse trabalho não podem ser generalizadas. No entanto, acredita-se que o presente estudo possa servir como impulso para análise de outras organizações públicas que implantaram ou desejam implantar ERP.

\section{Referências}

CARVALHO, Rodrigo Baroni de et al. Avaliação da implantação de erp: Estudo de caso de um hospital de grande porte. In: XXXII ENANPAD ENCONTRO DA ANPAD. Rio de Janeiro, 2008. Anais ..., 2008. Disponível em: <http://www.anpad.org.br/admin/pdf/ADI-A2807.pdf>. Acesso em: 12 de mar. 2017.

COLANGELO FILHO, Lucio. Implantação de sistemas ERP: um enfoque a longo prazo. São Paulo: Atlas, 2001.

EMPRESA DE PESQUISA AGROPECUÁRIA DE MINAS GERAIS - EPAMIG. Plano Diretor - EPAMIG. 2016. Disponível em: <http://www.epamig.br/>. Acesso em 22 out. 2016.

FERREIRA, David Luiz Silva et al. Implementação de um ERP em uma instituição pública de ensino superior: uma investigação sobre o ciclo de vida do sistema. Análise: Porto Alegre, v.23, n.3, p.270-283, set./dez. 2012

GIL, Antônio Carlos. Como elaborar projetos de pesquisa. 5. ed. São Paulo: Atlas, 2012.

GONÇALVES, G.; LIMA, I. A. Implantação de um sistema de informação enterprise resource planning (erp): estudo de caso em uma indústria eletrônica. Revista de Engenharia e Tecnologia. v. 2, 2010. p. 57-68. 
LAUDON, Kenneth C.; LAUDON, Jane P. Sistemas de Informação Gerenciais. 11. ed. São Paulo: Pearson Education do Brasil, 2014.

MONTEIRO, J. M.; SORDI, J. O. O Sistema ERP e a sua contribuição para a mudança de gestão das empresas: da gestão funcional para a gestão por processos. eGesta, v.2, n.2, abr.-jun./2001, p.9-68. Disponível em:

$\langle$ http://www.unisantos.br/mestrado/gestao/egesta/artigos/64.pdf $>$. Acesso em: $25 \mathrm{de}$ ago. 2016.

MOURA, Fábio L. et al. Aplicação do modelo de aceitação de tecnologia para avaliar a aceitação e o uso de software ERP. In: XIII International Conference on Engineering and Technology Education. Guimarães, March 2014. Anais ..., 2014.

O’BRIEN, James A.; MARAKAS, George M. Administração de Sistemas de Informação. 15. ed. São Paulo: AMGH, p. 269-280. 2013.

OZAKI, A. M.; VIDAL, A. G. R.. Desafios da Implementação de Sistemas ERP: Um estudo de caso em uma empresa de médio porte. In: SOUZA, Cesar Alexandre de; SACCOL, Amarolinda Zanela. (Org.). Sistemas ERP no Brasil (Enterprise Resource Planning): teoria e casos. São Paulo: Editora Atlas S.A, 2003. p. 285-303.

PTAK, Carol A. ERP: tools, Technologies, and applications for integrating the supply chain. Boca Raton: CRC Press LLC, 2004.

SACCOL, Amarolinda Zanela et al. Avaliação do impacto dos sistemas erp sobre variáveis estratégicas de grandes empresas no brasil. RAC. Revista de Administração Contemporânea (Impresso), Rio de Janeiro - RJ, v. 8, n. 1, p. 9-34, 2004.

SACCOL, Amarolinda Zanela et al. Mudanças organizacionais e sistema ERP. In: SOUZA, Cesar Alexandre de; SACCOL, Amarolinda Zanela. Introdução. Sistemas ERP no Brasil: (enterprise resource planning): teoria e casos. São Paulo: Atlas, p.173-190, 2003. 
SENA, A. S.; GUARNIERI, P. Enterprise Resource Planning governamental: a percepção dos servidores atuantes no Projeto Ciclo do Ministério da Justiça quanto à implementação. Revista de Administração Pública (Impresso), Rio de Janeiro RJ, v. 49, n. 1, p. 207-230, 2015. Disponível em: <http://bibliotecadigital.fgv.br/ojs/index.php/rap/article/view/42982>. Acesso em: 25 de ago. 2016.

SOUZA, César Alexandre de; ZWICKER, Ronaldo. Sistemas ERP: conceituação, ciclo de vida e estudos de casos comparados. In: Souza, César Alexandre de; Saccol, Amarolinda Zanela. (org.). Sistemas ERP no Brasil (Enterprise Resource Planning): teoria e casos. São Paulo: Editora Atlas S.A, p. 63-87, 2003.

YIN, R. K. Estudo de caso: planejamento e métodos. 2. ed. São Paulo: Bookman, 2002. 205 p.

\title{
Avaliação da implantação de um ERP em uma empresa pública: estudo de caso na EPAMIG
}

\section{Evaluation of the implementation of an ERP in a public company: a case study at EPAMIG}

\author{
Mateus Henrique de Aguiar Diniz ${ }^{3}$ \\ Adriane Maria Arantes de Carvalho ${ }^{4}$
}

\section{Resumo}

Atualmente os sistemas ERP têm fundamental importância na arquitetura de informação da maioria das empresas do setor privado. Os sistemas de gestão integrado podem ser vistos como uma ferramenta que organiza o fluxo de informações entre as diferentes atividades da empresa, facilitando a integração da informação e dos processos. Muitos estudos analisaram o processo de implantação dos sistemas ERP em empresas privadas, entretanto, poucas pesquisas têm-se dedicado à avaliação da implantação de sistemas ERP em empresas públicas. Assim, o principal objetivo deste artigo é avaliar a implantação de um sistema integrado de gestão na Empresa de Pesquisa Agropecuária de Minas Gerais (EPAMIG), destacando os cenários antes e depois da implantação do sistema ERP. Foi realizado um estudo de caso e a coleta de dados utilizou entrevistas e questionários. De acordo com os resultados, evidenciou-se que um sistema ERP trouxe

\footnotetext{
${ }^{3}$ Graduado em Sistemas de Informação pela Pontifícia Universidade Católica de Minas Gerais (PUC Minas).

${ }^{4}$ Doutora em Ciência da Informação pela Universidade Federal de Minas Gerais. Professora do Departamento de Administração da Pontifícia Universidade Católica de Minas Gerais (PUC Minas).
} 
melhorias significativas para o processo de requisição de material, com informações exatas e atualizadas, integração das informações entre os setores e a minimização do retrabalho. No entanto, foi identificada a dificuldade dos usuários em aprender a utilizar o sistema o que aponta para uma eventual falha no treinamento. Sugere-se que a organização estudada reveja a sua política de treinamento e de suporte, com a criação de instrumentos que permitam o registro e a solução dos problemas mais frequentes.

Palavras-chave: Enterprise resource planning (ERP). Processo de Requisição de Material. Gestão pública. Implantação de sistemas.

\begin{abstract}
Currently ERP systems have fundamental importance in the information architecture of most private sector companies. Integrated management systems can be seen as a tool that organizes the flow of information between the different activities of the company, facilitating the integration of information and processes. Many studies have analyzed the ERP systems implementation process in private companies, however, few studies have been devoted to the evaluation of the ERP systems implementation in public companies. Thus, the main objective of this article is to evaluate the implementation of an integrated management system at the Empresa de Pesquisa Agropecuária de Minas Gerais (EPAMIG), highlighting the scenarios before and after the implementation of the ERP system. A case study was conducted and the data collection used interviews and questionnaires. According to the results, it was evidenced that an ERP system brought significant improvements to the material requisition process, with accurate and updated information, integration of information among sectors and minimization of rework. However, it was identified the difficulty of users in learning to use the system which points to a possible failure in training. It is suggested that the organization could review its training and support policy, with the creation of tools to register the recording and resolution of the most frequent problems.
\end{abstract}

Key-words: Enterprise Resource Planning (ERP). Material Requisition Process. Public management. Deployment evaluation.

\title{
1 Introdução
}

Os sistemas de informação estão cada vez mais presentes nas organizações, tornando-se componentes imprescindíveis dos seus processos de negócio. De uma maneira em geral, o uso da tecnologia da informação junto à gestão tem produzido resultados positivos para as organizações, sejam elas privadas ou públicas. Os sistemas integrados de gestão, do inglês Enterprise Resource Planning (ERP), tornaram-se tendência e passaram a ser vistos como uma ferramenta de fundamental importância para proporcionar a agilidade necessária nesse contexto competitivo.

De acordo com Sena e Guarnieri (2015), a administração pública tem enfrentado diversos desafios no aprimoramento da gestão de seus processos, adotando novas 
práticas e tecnologias, e importando práticas consideradas bem-sucedidas, na iniciativa privada. A utilização de sistemas ERP no setor público ainda é restrita e poucos são os casos disponíveis na literatura. (FERREIRA et al, 2012). Porém o uso do ERP no setor público pode ser de grande importância para as organizações pois, como ressaltam Sena e Guarnieri (2015), a visibilidade interna e externa do fluxo de processos em uma organização pública proporciona o conhecimento exato dos fatos administrativos e de seus motivadores, levando a organização a um elevado nível de transparência e eliminando o retrabalho. No entanto, deve-se tomar muito cuidado ao implantar um ERP, pois a utilização desses sistemas se caracteriza por uma mudança organizacional, não apenas tecnológica.

Em Minas Gerais, a Empresa de Pesquisa Agropecuária de Minas Gerais (EPAMIG) vem utilizando um sistema ERP desde 2012. Após a implantação do ERP vários usuários vêm encontrando dificuldades em realizar algumas tarefas no sistema. Surgiram algumas indagações: os problemas apareceram porque os usuários tiveram dificuldades na adaptação ao novo processo ou têm resistência ao novo sistema? Ou ainda, por tratar-se de uma empresa pública, os usuários apresentam um comportamento de uso diferente dos observados na literatura para empresas privadas?

Com a finalidade de refletir sobre estas questões, o objetivo geral deste trabalho é analisar o impacto da implantação de um ERP na empresa EPAMIG, especificamente no processo de requisição de material. Para que se possa alcançar esse objetivo, foram estabelecidos os seguintes objetivos específicos: a) comparar o processo de requisição de material antes e depois da implantação do módulo ERP; b) avaliar a utilização do módulo pelos usuários.

A relevância deste trabalho está em apresentar uma análise do impacto de implantação de ERP numa empresa pública. Diante da falta de casos de encontrados na literatura sobre assunto, justifica-se a importância de pesquisas que procurem analisar a implantação de ERP não apenas no âmbito de organização privada, e também de contribuir para o entendimento do impacto percebido pelos usuários em relação a esse tipo de sistema.

\section{Sistemas Integrados de Gestão}

Os sistemas integrados de gestão (ERP), são considerados como uma ferramenta 
de Tecnologia da Informação (TI) que apoia o gerenciamento de informações. O’Brien e Marakas destacam que "o ERP é a espinha dorsal dos negócios eletrônicos, uma arquitetura de transmissão que liga todas as funções de uma empresa" (O’BRIEN; MARAKAS, 2013, p.269). Levando em consideração a perspectiva dos autores, pode-se dizer que um sistema ERP atua no planejamento de recursos empresariais e possui como principal função a informatização dos processos administrativos, conseguindo integrar os setores da empresa em um só ambiente de trabalho.

Souza e Zwicker (2003) entendem que os sistemas ERP podem ser definidos como sistemas de informação integrados, adquiridos na forma de pacotes comerciais de software de grande abrangência funcional. Para os autores, os sistemas ERP são geralmente divididos em módulos, que representam conjuntos de funções que normalmente atendem a um ou mais departamentos da empresa. Em muitas empresas existem sistemas específicos para cada departamento, que atendem às demandas internas dos mesmos, porém com a implantação de um ERP, os sistemas próprios de cada setor deixam de existir dando lugar a um único sistema que armazena, automatiza e gerencia todos os processos da empresa.

Tem-se que um ERP deve fornecer suporte à empresa controlando e integrando todos os seus processos. Neste sentido, Laudon e Laudon (2014) destacam que o ERP possibilita que ocorra um fluxo de informações contínuo único e consistente, de uma forma que atenda a organização como um todo. Assim sendo, Souza e Zwicker (2003) reiteram que um ERP necessita de um banco de dados unificado. Portanto, de uma forma geral, os dados que são utilizados por um módulo são armazenados no banco de dados unificado, para que assim possam ser utilizados por outros módulos caracterizando os ciclos de interações de informação entre os módulos, ou seja, integrando as informações da organização. Essa base de dados permite, então, ter uma melhor visão dos processos de qualquer área ou setor em tempo real e, com isso, o gerente detém informações precisas e oportunas para lhe apoiar na coordenação diária e na tomada de decisões gerenciais. Para Ptak (2004), um dos principais aspectos do ERP é justamente a sua habilidade em centralizar a informação relevante numa única base de dados.

\subsection{Implantação de sistemas ERP}

De acordo com Souza e Zwicker (2003), a adoção de um sistema ERP pela 
empresa envolve várias etapas. Estas baseiam-se num modelo de ciclo de vida de sistemas ERP, que envolve: a decisão de adoção do sistema e a escolha do software; sua implantação; sua utilização; e, finalmente, sua manutenção ou aprimoramento.

Decisão e seleção constituem uma mesma etapa do processo de implantação dos sistemas ERP porque a decisão de a empresa adotar ou não esse recurso ocorre concomitantemente com a seleção do fornecedor (SOUZA; ZWICKER, 2003).

A implementação é a segunda etapa do ciclo de vida de sistemas ERP e pode ser definida como o processo pelo qual os módulos do sistema são colocados em funcionamento na organização, o que significa iniciar a utilização do sistema no processamento de transações empresariais (SOUZA; ZWICKER, 2003). O processo de implementação é realizado em várias etapas de adaptação, uma para cada módulo ou grupo de módulos. É o momento no qual são realizados os procedimentos de ajuste do pacote ERP, ou seja, são realizadas modificações para que possam ser utilizados sob demanda em determinada empresa (SOUZA; ZWICKER, 2003).

O início da utilização do sistema exige que ele tenha sido adequadamente parametrizado, customizado (se necessário) e que: os funcionários que irão interagir com o sistema estejam devidamente treinados. Além disso as condições para obter suporte e auxílio devem ter sido disponibilizadas de forma adequada (SOUZA; ZWICKER, 2003).

Entre essas etapas, a implantação é, sem dúvida, a mais crítica do processo, uma vez que é a etapa que provoca mudanças na empresa. Além disso, ao considerar a etapa de manutenção como uma etapa de novas, periódicas e contínuas implantações, percebese mais uma vez sua importância. De acordo com Ptak (2004), um cuidadoso plano de implantação deve considerar as expectativas e receios dos stakeholders.

\subsubsection{Parâmetros para implantação}

Os projetos de implantação de sistemas empresariais integrados normalmente têm grande impacto sobre a empresa. Além disso, demandam grandes volumes de recursos humanos e financeiros (COLANGELO FILHO, 2001).

Segundo Colangelo Filho (2001), a implantação de um ERP é algo muito complexo, pois envolve muitas atividades e recursos, e sempre causa impacto na cultura da empresa provocando uma série de mudanças: na estrutura gerencial; nos processos de 
negócio; no modelo de gestão; e principalmente, nas pessoas. Por este motivo, o processo de implantação é estruturado através de um projeto. E como todo projeto, este, deve ser gerenciado de maneira adequada a fim de atingir seus objetivos previamente definidos.

A implantação é decisiva no que diz respeito à garantia do sucesso futuro do ERP. Um sistema implantado incorretamente pode fracassar quanto ao seu propósito inicial. Para Goncalves e Lima (2010) a organização não deve simplesmente achar que a implantação do sistema resolverá todos os seus problemas. Às vezes os problemas encontram-se nos próprios processos de negócio da empresa.

\subsubsection{Mudança organizacional decorrente da implantação do sistema ERP}

De acordo com Saccol et al (2003), a implantação do ERP três tipos de mudança: mudanças tecnológicas, relacionadas à mudança na tecnologia da informação e na qualidade da informação, nas técnicas e processos de trabalho, na qualificação das pessoas etc; mudanças estruturais, vinculadas a alterações nos mecanismos de coordenação, nas partes básicas das organizações e nos parâmetros de desenho das organizações; e mudanças comportamentais, associadas à mudança cultural, de visão departamental da organização para uma visão baseada em processos, do grau de motivação dos empregados e nas habilidades e capacidades requeridas das pessoas. Catellino et al, citado por Moura et al (2014) também destaca que são necessárias mudanças nos processos organizacionais, culturais e de negociação e enfatiza a importância da consideração de aspectos técnicos e não técnicos ligados ao ERP.

A implantação de um ERP afeta de uma maneira muito radical os processos, e até mesmo a cultura da empresa, portanto, deve-se ter uma atenção para lidar com essa mudança. Assim,

\footnotetext{
Ter simplesmente os processos-chave de negócios sob o controle de um sistema ERP não é condição sine qua non para a mudança de gestão, no entretanto, os estímulos criados pelo sistema, ainda de acordo com o próprio autor, constituem uma pressão constante sobre a gestão, no sentido de promover a mudança" (MONTEIRO; SORDI, 2006, p.42).
}

Na perspectiva de Monteiro e Sordi (2006), a adoção de um ERP propicia diversas melhorias, tais como: o controle maior sobre os processos operacionais; redução da burocracia ao nível mínimo; elevação do faturamento; redução do tempo de faturamento; redução do tempo de prestação de serviços de assistência técnica e a racionalização dos custos operacionais de assistência técnica e de vendas. No entanto, 
fica claro que junto com o sistema surgem algumas dificuldades como, por exemplo: encontrar no mercado profissionais com qualificação para atuar junto ao sistema; complexidade para a gestão integrada dos negócios, sendo necessário um bom índice de aceitação e uso do sistema pelos colaboradores da organização, pois o contrário poderá ocasionar no insucesso do investimento. Por melhor que seja o sistema, o retorno não será possível se os usuários não utilizarem o sistema. Por isso Ptak (2004) destaca que o projeto de implantação deve incluir o treinamento de todos os usuários, assim como deve lidar com possíveis objeções que eles apresentem.

De acordo com Saccol et al (2004), o ERP em si demonstra agregar valor em relação à variável produção (ganhos de produtividade, escala no uso de software etc.). Ele

oferece

também importantes contribuições para a eficácia organizacional e, especialmente, para a eficiência interorganizacional, facilitando a gestão, integração e comunicação entre diferentes unidades organizacionais.

\section{$5 \quad$ Procedimentos metodológicos}

Inicialmente foi realizado um levantamento bibliográfico e elaborado o referencial teórico sobre sistemas de gestão integrado. Optou-se pela pesquisa descritiva e o estudo de caso para alcançar os objetivos propostos. Para Gil (2012), as pesquisas descritivas têm como objetivo a descrição das características de determinada população, possibilitando o registro e a interpretação dos fatos, proporcionando assim uma nova visão sobre o cenário estudado. De acordo com Yin (2002), o estudo de caso é uma investigação empírica que investiga um fenômeno contemporâneo dentro de seu contexto da vida real, especialmente quando os limites entre o fenômeno e o contexto não estão claramente definidos como é o caso desse trabalho.

A unidade de análise foi a empresa EPAMIG - uma empresa do setor público, com sede situada na cidade de Belo Horizonte e várias unidades (fazendas) por todo o Estado de Minas Gerais. A escolha pela empresa decorre do fato do autor trabalhar na mesma. O sistema ERP implantado na EPAMIG atende a todas as fazendas e cerca de mil usuários, incluindo os funcionários da sede e os demais funcionários do interior.

O estudo de caso foi realizado por meio de observações feitas no próprio ambiente de trabalho, coleta da documentação do projeto ERP, realização de entrevistas 
e aplicação de questionários estruturados junto aos usuários do módulo de processos de requisição de material.

O roteiro de entrevista semiestruturado foi elaborado para analisar o processo de implantação e entender o cenário da empresa. A entrevista foi dividida em três partes relacionadas ao ciclo de vida do ERP: decisão e seleção; implementação; avaliação e uso do ERP. O roteiro do questionário possui dois blocos de itens. O primeiro bloco consiste em questões referentes ao sistema legado existente na empresa antes da adoção do sistema ERP. No segundo bloco foi adotado o modelo de Carvalho et al. (2008), com o acréscimo das perguntas 7 e 17. As perguntas foram agrupadas por assunto para auxiliar a análise dos dados, como pode ser visto no Quadro 1.

Quadro 1 - Categorias analíticas

\begin{tabular}{|c|c|}
\hline Categorias & Questões \\
\hline Facilidade & $5-10-11-13-14$ \\
\hline Produtividade & $6-21-22$ \\
\hline Utilidade & $7-8-9-15-16-17-19$ \\
\hline Controles internos & $12-18-20$ \\
\hline Satisfação & $23-24$ \\
\hline
\end{tabular}

Fonte: Elaborado pelos autores

A categoria Facilidade refere-se à facilidade de aprender e usar o sistema. Venkatesh et al, citado por Moura et al (2014), destaca que perguntas relacionadas à facilidade percebida pelo usuário dizem respeito a quanto de esforço deverá ser investido para que utilize o sistema. A categoria Utilidade, trata de como as informações do sistema são úteis. A utilidade percebida remete à crença de uma pessoa sobre o grau que a tecnologia melhorará seu desempenho na sua rotina de trabalho (VENKATESH et al, citado por MOURA et al, 2014). A categoria de Controles internos está relacionada com melhoria do controle das informações disponibilizadas. Na categoria Satisfação estão as perguntas sobre necessidades atendidas.

Foi utilizada uma escala Likert para buscar resultados de acordo com o grau de conformidade dos entrevistados. A escala Likert adotada tem 5 pontos onde cada nível recebeu uma pontuação ou peso, da seguinte maneira: Discordo com peso 1; Discordo com peso 2; Indiferente com peso 3; Concordo com peso 4; Concordo totalmente com 5.

A coleta dos dados ocorreu por meio de entrevistas com os três funcionários que ocupam os cargos de Coordenador web (Entrevistado 1), Coordenador de suporte 
(Entrevistado 2), e Coordenador de redes (Entrevistado 3). Eles atuam na Assessoria de Informática, trabalham na empresa há mais de 20 anos e participaram de todo o processo de informatização da empresa. A escolha dos respondentes da entrevista seguiu o critério de participação ativa em todo o processo de implantação do sistema. Elas ocorreram no segundo semestre de 2016.

No dia 03/05/2017, foi realizada mais uma entrevista com um Analista de sistemas (Entrevistado 4), que participou diretamente da segunda fase de implantação do ERP. Também foram utilizados documentos de todo o processo de implantação, possibilitando descrever o cenário básico da EPAMIG antes da implantação do sistema ERP.

Foram convidados a participar da pesquisa os funcionários da empresa que utilizam a Requisição de Material do módulo do ERP adquirido. O convite foi feito via e-mail, contando com uma carta de apresentação do estudo. O e-mail foi enviado para os cinquenta usuários ativos do módulo (população), tanto na sede como nas fazendas, e foram obtidas vinte e nove respostas (amostra). A partir do tamanho da população e do tamanho da amostra foi calculado a margem de erro do questionário que é de 11,91\%. O questionário foi construído no Google Forms e ficou disponibilizado entre os dias 12/05/2017 até 26/05/2017.

Desta maneira, a pesquisa de campo utilizou quatro fontes de evidências: a observação, a documentação do processo de implantação, a entrevista e os questionários, gerando análises de natureza quantitativa e qualitativa. Após a coleta dos dados eles foram tabulados utilizando uma planilha do Excel.

Com a definição dos pesos de cada item, foi calculada a média ponderada das respostas em cada questão utilizando o peso para a ponderação, assim como em Carvalho et al. (2008). Valores da média ponderada menores que 3 foram considerados como discordantes e, maiores que 3 , como concordantes, considerando a escala de 5 pontos. $\mathrm{O}$ valor exatamente 3 foi considerado indiferente. A seguir serão apresentados os resultados obtidos.

\section{Apresentação e análise dos dados}

A Empresa de Pesquisa Agropecuária de Minas Gerais (EPAMIG) é um órgão vinculado à Secretaria de Estado da Agricultura, Pecuária e Abastecimento do Estado de 
Minas Gerais. Seu propósito principal destina-se ao desenvolvimento a aplicação de pesquisa na área agrícola (tanto de culturas anuais como perenes e pecuárias).

A missão da empresa é pesquisar, capacitar e apresentar soluções e inovações tecnológicas para o desenvolvimento sustentável da agropecuária e da agroindústria, em benefício da sociedade. (EPAMIG, 2016). Alguns programas de pesquisa realizados pela empresa são nas áreas de: Agroenergia, Aquicultura, Cafeicultura, Floricultura, Fruticultura, Olericultura, Pesquisa em Bovinos, Processamento Agroindustrial, Silvicultura e Meio Ambiente.

Com o intuito de contribuir e aperfeiçoar vocações locais e regionais, todos estes programas envolvem a existência de Fazendas Experimentais, as quais encontram-se espalhadas por várias regiões do Estado.

\subsection{Cenário do Processo de Requisição de Material anterior à implantação do ERP}

O processo anterior de requisição de material partia da necessidade de repor algum material em qualquer setor da empresa. Então era aberta uma solicitação de material para o setor de almoxarifado, por meio de um formulário. O funcionário do setor preenchia o formulário de papel inserindo o código do material, nome e a quantidade desejada. Após isso o chefe do setor o assinava e o formulário era encaminhado, na maioria das vezes por um office boy, ao setor de almoxarifado. Assim que a solicitação chegava ao setor de destino, o funcionário consultava no estoque se existia o material, utilizando uma planilha. Caso o almoxarifado tivesse o material, ele o enviava ao solicitante. Caso não existisse esse material no estoque era feita uma ordem de compra (formulário a ser preenchido). Então era realizado o processo de compra e, com a chegada do material na empresa, ele era entregue ao setor solicitante.

As respostas relativas à situação antes da implantação do sistema ERP na EPAMIG, permitiram esboçar um panorama da situação, como pode ser visto na Tabela 1. Do total de vinte e nove respondentes, vinte e dois conheciam o processo anterior. Esta identificação foi possível pois a pergunta inicial do questionário era: "Você utilizou o antigo sistema de requisição de material?"”.

Observa-se que as questões 1 e 3 obtiveram médias menores que 3 e baixa taxa de dispersão, demonstrando que os usuários, no geral, não concordam que o sistema anterior facilitava o seu trabalho diário e que o fluxo de informações entre os setores era 
suficiente. Para eles muita informação ficava perdida ao longo do processo gerando atraso e retrabalho.

Tabela 1 - Situação antes da implantação do ERP

\begin{tabular}{c|c|c}
\hline \multicolumn{1}{c|}{ Questões } & \multicolumn{2}{c}{ Parâmetros } \\
\cline { 2 - 3 } & \multicolumn{1}{c}{$\begin{array}{c}\text { Média } \\
\text { ponderada }\end{array}$} & $\begin{array}{c}\text { Desvio } \\
\text { padrão }\end{array}$ \\
\hline $\begin{array}{l}\text { A forma de realizar uma requisição de material no sistema } \\
\text { anterior facilitava meu trabalho }\end{array}$ & 2,91 & 3,78 \\
\hline $\begin{array}{l}\text { Era fácil ou óbvio localizar as informações no sistema } \\
\text { anterior. }\end{array}$ & 4,73 & 6,99 \\
\hline $\begin{array}{l}\text { O fluxo de informações entre os setores era suficiente para } \\
\text { mantê-los alinhados. }\end{array}$ & 2,90 & 3,78 \\
\hline $4 \quad$ Estava satisfeito com o sistema anterior. & 3,45 & 3,29 \\
\hline
\end{tabular}

Fonte: dados da pesquisa

A pergunta 2 é a que mais chama atenção, pois uma parcela de usuários conseguia localizar as informações do sistema com facilidade, porém o alto grau de dispersão $(6,99)$, indica que esta facilidade para localizar as informações existia somente para alguns, ou seja, enquanto muitos usuários (dezesseis) conseguiam manusear as informações com extrema facilidade, outros encontravam dificuldades para conseguir acompanhar as informações no sistema.

A questão 4, relativa ao grau de satisfação do usuário com o sistema, obteve média de 3,45 e baixa dispersão, apontando que o sistema anterior era considerado relativamente bom, ou seja, aparentemente atendia as necessidades dos usuários.

\subsection{O processo de implantação do ERP}

A empresa passou por dois processos distintos: um de implantação inicial do sistema em 2005; e outro para a segunda fase de implantação em 2012. Num primeiro momento a chefia da Assessoria de Informática foi quem decidiu, junto à presidência da empresa, pela implantação do sistema da fornecedora RM Sistemas. Num segundo instante, quando ocorreu a entrada de uma nova chefia da Assessoria de Informática, a empresa passou pela segunda fase de implantação com o objetivo de implantar o sistema ERP de maneira completa.

\subsubsection{A decisão e escolha do ERP e a implantação inicial}


Antes da implantação do ERP a Assessoria de Informática desenvolvia vários tipos de soluções específicas para cada processo, variando de planilhas até pequenos sistemas. Porém estes sistemas não tinham integração entre si, ou seja, eram sistemas específicos e independentes.

De acordo com o Entrevistado 4, os gestores reclamavam da dificuldade de acesso à informação, bem como da demora em adquiri-las. O principal motivo da escolha do ERP foi a intenção de integrar suas áreas (estoque, compras, patrimônio, financeiro, contábil, fiscal e folha de pagamento), de ter um melhor controle das unidades descentralizadas/filiais e, consequentemente, de gerenciar melhor a empresa. $\mathrm{Na}$ época foi solicitado um orçamento a três empresas fornecedoras desse tipo de sistema.

Em meados 2005, após a etapa de seleção, os gestores fecharam contrato com a RM Sistemas. A implantação inicial deu-se em no fim de 2005. Ela apresentou alguns problemas, tais como: falta de documentação de processos internos; pausas no projeto a cada troca de chefias; resistência de funcionários quanto a essa nova tecnologia; falta de comprometimento de alguns setores; e um aumento no prazo decorrente da compra da empresa fornecedora por outra, que acarretou um atraso de cerca de dois anos de duração. Os diversos problemas enfrentados ocasionaram um atraso no cronograma e, consequentemente, um aumento no valor do projeto. Foram implantados somente dois módulos de maneira completa: RM Folha (Módulo referente à Folha de Pagamentos) e RM Liber (Módulo referente à Gestão Fiscal). Os demais módulos ficaram sem conclusão.

De acordo com os Entrevistados 1, 2 e 3, a falta de comprometimento e resistência à tecnologia de alguns funcionários, somados à falta de documentação de processos, comprometeu a fase de levantamento de requisitos. Por esse motivo vários processos não foram incluídos no sistema. Alguns dos processos incluídos, como por exemplo, o processo de requisição de material foram inseridos de maneira incompleta no sistema.

\subsubsection{A segunda fase de implantação do ERP}

Em 2012, com a entrada de uma nova chefia da Assessoria de Informática, a empresa passou pela segunda fase de implantação. Conforme o Entrevistado 4, o seu 
objetivo principal era: obter a melhoria na execução dos processos; e correção daqueles que não se encontravam no sistema, realizando a devida integração entre as áreas. A decisão foi continuar com o ERP já implantado e reestruturá-lo de forma a integrar seus módulos. Então ocorreu a implantação completa do sistema ERP.

A segunda fase de implantação teve início no primeiro semestre de 2012 e durou 1 ano e 7 meses, tendo entrado em operação em 01 de janeiro de 2014. Os módulos foram implantados separadamente, sob demanda, das áreas afins. A própria empresa fornecedora disponibilizou seus analistas/consultores que apoiaram a empresa durante a implantação.

Segundo o Entrevistado 4, o principal desafio foi fazer com que os usuários se envolvessem com a implantação, de modo a alinhar as informações necessárias para a estruturação dos processos e executar as tarefas do projeto. Ainda de acordo com o entrevistado, o impacto maior ocorreu nos setores de Compras, Estoque e Almoxarifado,

responsáveis pela entrada de mercadoria/serviços da empresa. Isso ocorreu porque os processos tinham sido inseridos no sistema anterior de maneira incompleta, gerando assim maior dificuldade para os usuários, já que a partir da implantação completa do módulo, ele passou a ser integrado aos demais módulos do sistema.

Nesta fase, a equipe da fornecedora do sistema e a Assessoria de Informática da EPAMIG criaram um cronograma seguindo a metodologia de implantação da própria fornecedora do sistema. Dessa forma, foram levantados e documentados, novamente, todos os processos existentes na empresa. Os procedimentos de levantamento de processos foram realizados por meio de entrevistas com os funcionários de cada área.

Segundo os entrevistados, mais uma vez a resistência dos funcionários a fornecer informações para o projeto da segunda fase de implantação foi um dos pontos mais difíceis. Apesar das dificuldades os processos foram totalmente revitalizados, incluindo o processo de requisição de material que, dessa vez, havia sido parametrizado no sistema.

Quanto ao treinamento de usuários, o entrevistado, explicou que o treinamento ocorreu apenas com os usuários-chave e estes repassaram o conhecimento para seus colegas de trabalho. No entanto, no caso de algum usuário sentir a necessidade de algum treinamento, ele pode requisitá-lo junto ao departamento de Recursos Humanos. 


\subsubsection{O uso do sistema}

Após a segunda fase de implantação do sistema ERP, o processo de requisição de material passou a acontecer da seguinte forma: quando surge a necessidade de algum material, dentro de qualquer setor da empresa, é aberta uma solicitação de material através do sistema. O funcionário realiza login no sistema e seleciona o material desejado. De maneira automática é realizada a abertura de um workflow. O sistema aguarda aprovação da chefia do setor para prosseguir para próxima etapa. Assim que a chefia aprova a movimentação, a solicitação é exibida para o setor de almoxarifado. A equipe do setor de destino recebe o workflow, que fará de maneira automática a verificação da existência do material no estoque e, caso exista o material em estoque, o funcionário do setor deve aprovar a solicitação, fazendo o recebimento desse movimento para o processo de Baixa de Estoque/Entrega de Material, no qual o workflow é encerrado e o material entregue. Caso o material não conste no estoque, o responsável pelo Almoxarifado encerrará o workflow e em seguida receberá a requisição para o processo de solicitação de compras. Será realizado todo o processo de compra do material e após chegada do material, ele é entregue para o setor solicitante, sendo encerrado o workflow.

De acordo com todos os entrevistados, é possível identificar alguns benefícios após a segunda fase de implantação do sistema ERP, como por exemplo: evita o retrabalho; minimiza o risco de erro; torna a informação disponível no sistema; permite maior controle dos gastos e receitas. No entanto, eles destacam que para melhorar o gerenciamento da empresa deve haver o empenho de todos os colaboradores envolvidos no projeto.

Ao serem indagados sobre a situação após a implantação do sistema ERP na EPAMIG, os respondentes permitiram esboçar um panorama da situação, conforme a Tabela 2.

Observa-se que as perguntas relacionadas à facilidade (questões 5, 10, 11, $13 \mathrm{e}$ 14) têm médias superiores a 3, com exceção de duas perguntas específicas (questões 10 e 11) que tratam da facilidade de usar e aprender. A questão 5, obteve média de 3,79 e baixa dispersão, apontando que os usuários notaram uma facilidade maior ao utilizar o sistema ERP no dia a dia, quando se compara com o resultado obtido na questão 1. As questões 13 e 14, tiveram médias de 3,00 e 3,28 e a taxa de dispersão muito baixa, apontando que eles consideravam mais fácil localizar a informação no sistema anterior, 
conforme resultado obtido na questão 1 .

As perguntas que abordam a facilidade de aprender e utilizar o sistema (questões 10 e 11) apresentaram as menores médias do questionário - 2,03 e 2,31 respectivamente - e baixa taxa de dispersão, demonstrando que os usuários, no geral, não concordam que o sistema ERP é fácil de usar ou de aprender como usar. Isso demonstra que o sistema ERP requer treinamento para os funcionários, pois possui uma curva de aprendizado grande.

Em relação à utilidade que o sistema ERP gerou após sua implantação (questões 7, 8, 9, 15, 16, 17 e 19), obteve-se média ponderada elevada. Este resultado demonstra que, apesar das dificuldades encontradas durante o processo implantação, os usuários acreditam que o sistema proporciona melhorias para ajudá-lo a desempenhar o seu trabalho, com a consolidação da informação, evitando inconsistências e redundâncias, e principalmente reduzindo a complexidade dos processos. No entanto, vale ressaltar a importância de conhecer o funcionamento do processo de requisição de material, pois a medida que tem-se domínio sobre o funcionamento do processo, mais simples fica o entendimento do mesmo no sistemaERP. Esse resultado é semelhante ao obtido por Ferreira et al (2012) num caso de implantação do ERP numa instituição pública de ensino superior. Os usuários que apresentaram dificuldades em utilizar o ERP, a associaram ao fato da preparação (treinamento) ter sido deficiente.

\section{Tabela 2 - Situação depois da implantação do ERP}




\begin{tabular}{|c|c|c|c|}
\hline \multicolumn{2}{|r|}{ Questões } & \multicolumn{2}{|c|}{ Parâmetros } \\
\hline & & $\begin{array}{c}\text { Média } \\
\text { ponderada }\end{array}$ & $\begin{array}{l}\text { Desvio } \\
\text { padrão }\end{array}$ \\
\hline 5 & O sistema ERP facilita o meu trabalho diário. & 3,79 & 4,76 \\
\hline 6 & $\begin{array}{l}\text { O sistema ERP permite que eu realize tarefas mais } \\
\text { rapidamente, aumentando a minhaprodutividade. }\end{array}$ & 3,83 & 5,26 \\
\hline 7 & $\begin{array}{l}\text { Conheço o funcionamento de todo o processo de } \\
\text { requisição de material no sistema ERP. }\end{array}$ & 4,34 & 6,65 \\
\hline 8 & $\begin{array}{l}\text { O sistema ERP permite que eu melhore a qualidade do } \\
\text { meu trabalho. }\end{array}$ & 4,00 & 5,89 \\
\hline 9 & $\begin{array}{l}\text { Considero o sistema ERP muito útil para minhas } \\
\text { atividades. }\end{array}$ & 4,34 & 7,53 \\
\hline 10 & É fácil e rápido aprender como usar o sistema ERP. & 2,03 & 6,87 \\
\hline 11 & Considero o sistema ERP fácil de usar. & 2,31 & 3,96 \\
\hline 12 & $\begin{array}{l}\text { O sistema ERP possui informações exatas, atualizadas e } \\
\text { em um nível apropriado de detalhamento. }\end{array}$ & 4,45 & 8,11 \\
\hline 13 & É fácil localizar informações no sistema ERP. & 3,00 & 2,39 \\
\hline 14 & $\begin{array}{l}\text { O significado de uma informação disponível no sistema } \\
\text { ERP é fácil de localizar ou então é óbvio. }\end{array}$ & 3,28 & 1,92 \\
\hline 15 & $\begin{array}{l}\text { O sistema ERP permite a comparação e consolidação de } \\
\text { informações, sem gerar inconsistências. }\end{array}$ & 3,83 & 5,22 \\
\hline 16 & $\begin{array}{l}\text { A implantação do ERP gerou impactos positivos nas } \\
\text { rotinas de trabalho da organização. }\end{array}$ & 4,00 & 5,07 \\
\hline 17 & O sistema ERP reduz a complexidade dos processos. & 3,97 & 5,36 \\
\hline 18 & $\begin{array}{l}\text { Houve uma melhoria significativa nos controles internos } \\
\text { da empresa gerada pelo sistema ERP. }\end{array}$ & 3,93 & 4,82 \\
\hline 19 & $\begin{array}{l}\text { O sistema ERP permite a integração de todas as } \\
\text { informações das diversas áreas da empresa. }\end{array}$ & 4,21 & 6,38 \\
\hline 20 & $\begin{array}{l}\text { O fluxo das informações entre os setores está mais } \\
\text { organizado por causado sistema ERP. }\end{array}$ & 4,00 & 5,63 \\
\hline 21 & $\begin{array}{l}\text { Com o sistema ERP, foi possível minimizar o retrabalho e } \\
\text { a redundância de informações. }\end{array}$ & 4,14 & 6,06 \\
\hline 22 & $\begin{array}{l}\text { É rápido obter informações, pois o sistema ERP é muito } \\
\text { ágil. }\end{array}$ & 3,93 & 5,54 \\
\hline 23 & $\begin{array}{l}\text { O sistema ERP atende plenamente as minhas necessidades, } \\
\text { do meu setor e da empresa. }\end{array}$ & 4,14 & 6,10 \\
\hline 24 & $\begin{array}{l}\text { Estou plenamente satisfeito com o sistema ERP im } \\
\text { plantado atualmente na empresa }\end{array}$ & 4,14 & 5,85 \\
\hline
\end{tabular}


Fonte: Dados da pesquisa

É possível observar que os itens relacionados à controles internos (questões 12, 18 e 20) são os que obtiveram a maior média dos dados. Esses resultados reforçam a ideia que o ERP trouxe benefícios para o dia a dia dos funcionários, principalmente se comparado ao cenário anterior. $\mathrm{Na}$ primeira parte do questionário, a pergunta relacionada à melhoria dos controles internos indicou uma média inferior a 3 e com um baixo grau de dispersão, evidenciando o descontentamento dos usuários com relação a desorganização da informação. Por sua vez, após a implantação do ERP, esta média subiu significativamente, deixando claro que agora os usuários possuem um controle maior para gerenciar as informações necessárias e principalmente para manter os setores integrados e bem alinhados. Convém ressaltar a alta taxa de dispersão na pergunta 12 , confirmando que a grande maioria dos funcionários (vinte), acreditam que o sistema ERP possui informações exatas e sempre atualizadas.

Conforme os resultados apresentados os usuários estão satisfeitos com a implantação do sistema ERP. Isso pode ser comprovado através das médias 4,14 e 4,14 respectivamente, para as perguntas relacionadas à satisfação do usuário. Se antes da implantação os usuários estavam conformados com o sistema anterior, após a implantação do sistema, ficou claro que as melhorias trazidas junto ao ERP, deixaram os usuários com um nível de satisfação elevado.

No geral, nota-se que grande parte das médias foram elevadas, demonstrando um grau de concordância dos usuários quantos aos benefícios do ERP para a empresa e vai de encontro com as opiniões dos entrevistados que indicaram vários benefícios obtidos com a utilização do sistema ERP.

\section{Considerações finais}

O estudo tinha como objetivo a análise do impacto de implantação de ERP numa empresa pública, a EPAMIG. Foi possível comparar o processo de requisição de material antes e depois da implantação do módulo ERP. Convém ressaltar que não houve nenhum tipo de restrição por parte da empresa para a realização do estudo. A limitação mostrou-se presente somente para a coleta de dados por meio de entrevistas e/ou questionários. Os funcionários muitas das vezes não tinham disponibilidade para responder as questões. No entanto, apesar da margem de erro da pesquisa ser de $11,91 \%$, os dados permitem apontar algumas tendências com relação ao uso do módulo 
ERP estudado.

Observou-se que, de acordo com as respostas do grupo de questões "Produtividade", o processo de requisição de material ficou mais ágil após a implantação do sistema ERP, beneficiando o trabalho diário dos funcionários e fazendo com que se tenham informações atualizadas e consolidadas. Acrescenta-se ainda que no que se refere a "Controles internos", a implantação do sistema ERP na EPAMIG beneficiou a gestão do processo contribuindo na melhoria da comunicação entre os setores bem como a organização de todas as informações. Nota-se também, que após a implantação do sistema, houve a integração de informações entre diversas áreas. Além disso permitiu a comparação e consolidação de informações, gerando assim ganhos na qualidade do trabalho dos funcionários, conforme as respostas do grupo de "Utilidade".

Pode-se inferir que os usuários tiveram retorno satisfatório sobre a implantação do ERP, já que as questões do grupo "Satisfação" obtiveram grande maioria das respostas como positivas (médias acima de 3). Porém percebe-se que, segundo o grupo de questões "Facilidade", os funcionários tiveram dificuldades em aprender a utilizar o novo sistema o que impacta diretamente em sua utilização diária. Ressalta-se o destaque negativo, indicado pelos usuários, que trata das perguntas 10 e 11 que obtiveram as menores médias e ambas estão relacionadas à facilidade de uso do sistema. Estas perguntas deixam claro que o treinamento passado ao usuário não foi suficiente para o seu entendimento quanto aos processos do sistema ERP. Ressalta-se aqui a importância do treinamento para a consolidação do conhecimento sobre o processo e sobre a utilização do sistema. Para que isso venha a ocorrer sugere-se que a organização estudada reveja a sua política de treinamento e de suporte, com a criação de instrumentos que permitam o registro e a solução dos problemas mais frequentes.

Em se tratando de um estudo de caso, as conclusões desse trabalho não podem ser generalizadas. No entanto, acredita-se que o presente estudo possa servir como impulso para análise de outras organizações públicas que implantaram ou desejam implantar ERP.

\section{Referências}

CARVALHO, Rodrigo Baroni de et al. Avaliação da implantação de erp: Estudo de caso de um hospital de grande porte. In: XXXII ENANPAD ENCONTRO DA 
ANPAD. Rio de Janeiro, 2008. Anais .., 2008. Disponível em: <http://www.anpad.org.br/admin/pdf/ADI-A2807.pdf>. Acesso em: 12 de mar. 2017.

COLANGELO FILHO, Lucio. Implantação de sistemas ERP: um enfoque a longo prazo. São Paulo: Atlas, 2001.

EMPRESA DE PESQUISA AGROPECUÁRIA DE MINAS GERAIS - EPAMIG. Plano Diretor - EPAMIG. 2016. Disponível em: 〈http://www.epamig.br/>. Acesso em 22 out. 2016.

FERREIRA, David Luiz Silva et al. Implementação de um ERP em uma instituição pública de ensino superior: uma investigação sobre o ciclo de vida do sistema. Análise: Porto Alegre, v.23, n.3, p.270-283, set./dez. 2012

GIL, Antônio Carlos. Como elaborar projetos de pesquisa. 5. ed. São Paulo: Atlas, 2012.

GONÇALVES, G.; LIMA, I. A. Implantação de um sistema de informação enterprise resource planning (erp): estudo de caso em uma indústria eletrônica. Revista de Engenharia e Tecnologia. v. 2, 2010. p. 57-68.

LAUDON, Kenneth C.; LAUDON, Jane P. Sistemas de Informação Gerenciais. 11. ed. São Paulo: Pearson Education do Brasil, 2014.

MONTEIRO, J. M.; SORDI, J. O. O Sistema ERP e a sua contribuição para a mudança de gestão das empresas: da gestão funcional para a gestão por processos. eGesta, v.2, n.2, abr.-jun./2001, p.9-68. Disponível em:

〈http://www.unisantos.br/mestrado/gestao/egesta/artigos/64.pdf $>$. Acesso em: 25 de ago. 2016.

MOURA, Fábio L. et al. Aplicação do modelo de aceitação de tecnologia para avaliar a aceitação e o uso de software ERP. In: XIII International Conference on Engineering and Technology Education. Guimarães, March 2014. Anais ..., 2014. 
O’BRIEN, James A.; MARAKAS, George M. Administração de Sistemas de Informação. 15. ed. São Paulo: AMGH, p. 269-280. 2013.

OZAKI, A. M.; VIDAL, A. G. R.. Desafios da Implementação de Sistemas ERP: Um estudo de caso em uma empresa de médio porte. In: SOUZA, Cesar Alexandre de; SACCOL, Amarolinda Zanela. (Org.). Sistemas ERP no Brasil (Enterprise Resource Planning): teoria e casos. São Paulo: Editora Atlas S.A, 2003. p. 285-303.

PTAK, Carol A. ERP: tools, Technologies, and applications for integrating the supply chain. Boca Raton: CRC Press LLC, 2004.

SACCOL, Amarolinda Zanela et al. Avaliação do impacto dos sistemas erp sobre variáveis estratégicas de grandes empresas no brasil. RAC. Revista de Administração Contemporânea (Impresso), Rio de Janeiro - RJ, v. 8, n. 1, p. 9-34, 2004.

SACCOL, Amarolinda Zanela et al. Mudanças organizacionais e sistema ERP. In: SOUZA, Cesar Alexandre de; SACCOL, Amarolinda Zanela. Introdução. Sistemas ERP no Brasil: (enterprise resource planning): teoria e casos. São Paulo: Atlas, p.173-190, 2003.

SENA, A. S.; GUARNIERI, P. Enterprise Resource Planning governamental: a percepção dos servidores atuantes no Projeto Ciclo do Ministério da Justiça quanto à implementação. Revista de Administração Pública (Impresso), Rio de Janeiro RJ, v. 49, n. 1, p. 207-230, 2015. Disponível em: <http://bibliotecadigital.fgv.br/ojs/index.php/rap/article/view/42982>. Acesso em: 25 de ago. 2016.

SOUZA, César Alexandre de; ZWICKER, Ronaldo. Sistemas ERP: conceituação, ciclo de vida e estudos de casos comparados. In: Souza, César Alexandre de; Saccol, Amarolinda Zanela. (org.). Sistemas ERP no Brasil (Enterprise Resource Planning): teoria e casos. São Paulo: Editora Atlas S.A, p. 63-87, 2003.

YIN, R. K. Estudo de caso: planejamento e métodos. 2. ed. São Paulo: Bookman, 
2002. 205 p. 